\title{
The Psychosocial Impact of Covid-19 on Students, Teachers, and Families
}

\author{
Aprajita Dixit* and Anushka Agnihotri \\ Department of Mental Health and Life Skills Promotion, Moolchand Medcity, Delhi, India
}

Email of corresponding author: aprajitadixit18@gmail.com

\begin{abstract}
For the uninitiated, Coronavirus disease 2019, popularly referred to as Covid-19, is an infectious respiratory disease, primarily transmitted through close contact. In general, the rapid spread of coronavirus disease has significantly altered the daily routines of people all over the world. A large number of changes, many of which have health concerns as causes, are bound to generate anxiety and panic in people. A fear is being experienced by everyone in these trying times, despite the large number of precautions available at one's disposal. Education in the Covid-Era has turned out to be a tricky business, and expectedly, students feel burdened with keeping up with their studies in the middle of a global pandemic. Teachers aren't immune to Covid's psychosocial impacts either. While the 'online classes' may have been uncomfortable- and impractical- for some students, they've proven to be more stressful for teachers, who aren't as familiar with technology as the former. Families have especially gone through a myriad of changes in the Covid era. These changes have had both positive and negative psychosocial impacts on the family members.
\end{abstract}

Keywords: Coronavirus; Students; Teachers; Families; Positive; Negative; Impact.

\section{INTRODUCTION}

For the uninitiated, Coronavirus disease 2019, popularly referred to as Covid-19, is an infectious respiratory disease, primarily transmitted through close contact. Its origin can be traced to Wuhan, China where the first confirmed case was reported, and has since resulted in a pandemic, with more than 13.6 million deaths as of July $16^{\text {th }}, 2020$.

It is human nature to respond to potentially threatening and unfamiliar situations with emotions of fear, stress and worry. Therefore, it comes as no surprise that the wide spread of the 'Covid-19 pandemic' has taken a toll on the mental health of most people. The damage caused by the virus has been viewed majorly in biological terms; however, its ramifications on other facets of human life cannot be ignored. This article talks about the psychosocial impacts of the pandemic on humans, focusing specifically on students, teachers, and families.

\section{COVID-19 AND MENTAL HEALTH}

In general, the rapid spread of coronavirus disease has significantly altered the daily routines of people all over the world. A large number of changes, many of which have health concerns as causes, are bound to generate anxiety and panic in people. A fear is being experienced by everyone in these trying times, despite the large number of precautions available at one's disposal.

For many, an almost worldwide lockdown, alien rules of social distancing which seem to have robbed them off their 'support system' and an atmosphere of uncertainty are unprecedented situations that they are struggling to come to terms with.

Those who have been infected by the disease have a more tragic story to tell. Even after successfully defeating the virus itself, they find themselves fighting another, and often, a stronger enemy- stigma.

There have been many cases where patients have gone to extreme lengths to avoid stigma. Case in point, Telangana where it was reported on July $16^{\text {th }}$ that over two thousand patients have gone missing after being tested positive for Covid over the past two weeks to avoid facing discrimination at the hands of society. They had opted for home isolation, and have since gone missing, even turning their phones off to avoid being tracked down.

While it is true that people should behave more responsibly, especially when it concerns both their as well as the health of others, one cannot ignore the obvious cause behind such behaviours. 
This statement is corroborated by the onslaught of racism and hatred experienced by Asian people worldwide after the virus began to make its presence felt. The attacks were justified on the basis of them having 'Chinese-like facial features', adding to the popular narrative of pinning the blame on China for the pandemic.

Closer to home, many people of North East were targeted for their physical appearance after Coronavirus spread. On Wednesday, March $25^{\text {th }}$, a 40-year-old man was arrested in North-west Delhi for allegedly calling a Manipuri girl 'coronavirus' and subsequently spitting on her face. Incidents such as these, fuelled by prejudice and barely concealed racism, have serious ramifications, including but not limited to, harming one's selfesteem, inducing in them a sense of humiliation and shame, as well as pitting communities against each other in situations when it is pressingly urgent to stay united.

Following is a closer look at the psychosocial impacts of the spread- focusing majorly on the students, teachers and families.

\section{THE STUDENTS}

Education in the Covid-Era has turned out to be a tricky business, and expectedly, students feel burdened with keeping up with their studies in the middle of a global pandemic.

The aforementioned changes have certainly not left the lives of students untouched. For one, their conventional classroom classes have been replaced by the less appealing online classes. While it may sound like the ideal method of class-taking to some, it has caused a spike in stress levels for some lesser privileged students, who do not have access to the required resources. For them, online classes are, in more ways than one, an evidence of their 'inferiority' as compared to the more privileged students who are better equipped with technology.

A major problem reported by students is the absence of in person interaction with their peers. Since students are used to seeing their friends every day, and often share close, emotional bonds with them; a sudden 'cut off' of sorts is bound to impact them. It can lead to development of feelings of alienation, loss and, in severe cases, depression.
Quoting the findings of a research conducted by Dr. Simon Williams, Public Health Researcher at Swansea University, even after as little as two weeks, people were found to be struggling with the loss of social interaction.

It will not be wrong to say that social distancing, though effective to some extent as a precaution, has come at a great cost to people's mental health, especially students, with ages ranging from anywhere between 12-22, as they are considered to be more dependent on their relationships.

Study has shown that the loss of social interaction are having a knock- on effect in the form of emotional losses, such as a loss of selfworth, loss of motivation and a loss of meaning in daily life.

Examinations are another issue. As proved in the All India Senior Secondary Central Examinations held by CBSE, the uncertainty in conduction of exams, caused by the virus, had a negative impact on students. Exams were initially postponed, with repeated assurances that they will be conducted once the situation normalised, before finally having to be cancelled. The events caused a tremendous amount of stress to students who were confused by the changes, and what it meant for their future.

However, there have been silver linings. Students with social anxiety, and those with special needs are said to have benefitted from the 'online classroom' experiment. It has come to them as a better alternative where they are more comfortable, as compared to in a traditional classroom where they had felt the pressure of competing with other students, often putting their mental health at risk.

\section{THE TEACHERS}

Teachers aren't immune to Covid's psychosocial impacts either. While the 'online classes' may have been uncomfortable- and impractical- for some students, they've proven to be more stressful for teachers, who aren't as familiar with technology as the former. They also hold that the online classes cannot be considered a viable alternative to the conventional methods of teaching, as it excludes face-to-face interaction, which they believe is an important aspect of the learning process. 
Cases of harassment of teachers by students have been reported, evidently causing huge amounts of stress and humiliation to them. These incidents of harassment have taken place in the online classes that had become the need of the hour. Students have been making fake accounts and joining classes, hurling abuses and slangs at the teacher.

In the context of the pandemic, many government teachers in the country have been called 'covid warriors' as they've been allotted duties to provide relief to the people, including distribution of ration, cooked food, as well as volunteering in the isolation centres.

While a work force is an essential requirement in these times, it is also necessary to look at the effects of these duties on one's mind.

Coming in contact with many people, most of whom have not been tested for the virus, has caused heightened anxiety among the teachers, even after taking all possible precautions to minimise the risk of infection.

With the closing of borders and other travel restrictions, commuting has proved to be stressful as well for teachers who work in neighbouring states. Acquiring the required permissions is a tedious affair, and often time consuming too.

\section{THE FAMILIES}

Families have especially gone through a myriad of changes in the Covid era. These changes have had both positive and negative psychosocial impacts on the family members.

For one, the shift from office to 'work from home', as well as shutting down of educational institutions have led to increased family time. People are spending more time bonding with their families, often engaging in activities like playing games and cooking, among trying other hobbies together. These activities, as well as the available family support and meaningful bonds have come to be accepted as great methods of combating stress

This complicates the situation further for families where one or more members struggle with addiction. These families are unable to seek the required help for the patient as well as themselves, and consequently, it has disastrous effects on their mental health. and anxiety prevalent in the midst of the health emergency.

This may be a time of addressing family issues that have earlier been brushed under the carpet. Due to spending more time together, people are more likely to start conversations about problems they had earlier been ignoring. The outcome depends on how the issue is addressed, but it can certainly be a means of catharsis for family members.

Things have taken a turn for worse in families with domestic violence and abusive households. Social distancing and strict lockdown rules have cut off victims of abuse from any outside support, who find themselves trapped in the confines of their house with their abuser.

During the first four phases of the Covid-19 lockdown related lockdown, Indian women filed more domestic violence complaints than recorded in a similar period in the last ten years. In 2020, between March 25 and May 31, 1,477 complaints of domestic violence were made by women.

Abusers often control their victims by isolating them from their support system, a task made much easier with the policy of lockdown. More than 92,000 SOS calls were received by the Childline India helpline asking for protection from abuse and violence as of April 15 ${ }^{\text {th }}, 2020$. According to Harleen Walia, Deputy Director of Childline India, the number of calls on the helpline since the lockdown have increased by $50 \%$.

Substance abuse is another problem that needs to be addressed. In the lockdown that has followed the outbreak of the disease, many patients suffering from drug and alcohol addiction have relapsed.

The UK Addiction Treatment Group, also known as the UKAT, has revealed that admissions into its seven residential rehabilitation facilities across the country has reduced by almost $20 \%$ in the month of April, 2020 alone. It has predicted a surge in the number of people relapsing back into alcohol and drug abuse.

In more tragic news, suicides and suicide attempts are seeing a steep rise in numbers too. In Kolkata alone, 113 cases of suicide were reported between April and May 2020, more than double the number for the same period last year. Over half of these were 40 -year-old or younger. 
It has been noted that they were 'fighting helplessness and uncertainty', a condition which has become prevailing since the Covid-19 pandemic began, bringing with it months long lockdowns and economic misery.

With the onset of the disease, many lost their jobs- adding to the already present anxiety about the virus. For family holders, this was particularly upsetting as they have the responsibility of the family. Economic problems have even pushed some to the brink of depression. Senior psychologist Subir Hajra Chaudhuri has revealed that some patients suffering from chronic depression have relapsed during the lockdown as it limited their access to mental healthcare.
It is more important now than ever, for family members to provide unconditional love and regard to each other, and reach out for help whenever necessary.

\section{CONCLUSION}

It is thus evident that with the onset of the Covid pandemic, a Mental Health pandemic has also taken the world by storm. Mental health professionals are bending over backwards to manage the crisis, but it is a difficult feat to achieve without our support. It is the need of the hour for communities to come together, provide support and warmth to ones in need and create a more accepting world for all.

\section{REFERENCES}

[1] "Home | Ministry of Health and Family Welfare | GOI" (2020, April 8). Retrieved from www.mohfw.gov.in.. (accessed on 8th April 2020).

[2] A Manual for Parents and Caregivers. Retrieved from https://www.unicef.orgs/india/media/3401/file/ PSSCOVID19-Manual-ChildLine.pdf.

[3] Banerjee, D. (2020). Psychological preparedness for the COVID-19 pandemic, perspectives from India. Psychiatry Research. 288 (2020) 112999.

[4] Bhattacharya, S. (2020). Children among biggest victims of Covid-19 lockdown with multiple side-effects: CRY report, Hindustan Times.

[5] Bhuyan, A. (2020, April 9). Caring for the carers during the Covid-19 pandemic. Livemint. Retrieved from https://www.livemint.com/

[6] Cleaning Workers are on the Front Lines of the Coronavirus Pandemic (2020, March 20), Occupational Health and Safety. Retrieved from https://ohsonline.com/.

[7] Covid 19 Stress: Cop shoots self, 4 others commit suicide in Maharashtra (2020, April 12), Times of India. Retrieved from https://timesofindia.indiatimes.com/

[8] Dasgupta, S. (2020, April 29). Not enough masks \& gloves, sanitation workers fear infection at Delhi's Covid hospitals, The Print. Retrieved from https://theprint.in/india

[9] Lee, J. (2020). Mental health effects of school closures during COVID-19. The Lancet: Child and Adolescent Health, 4(6), 421. https://doi.org/10.1016/s2352-4642(20)30109-7

[10] Mock, J. (2020, June 1). Psychological Trauma Is the Next Crisis for Coronavirus Health Workers. Scientific American. Retrieved from https://www.scientificamerican.com/article/psychol ogical-trauma-is-the-next-crisisfor-coronavirus-health-workers $1 /$.

[11] Montemurro, N. (2020). The emotional impact of COVID-19: From medical staff to common people. Elsevier Public Health Emergency Collection. https://doi.org/10.1016/j.bbi.2020.03.032

[12] National Institute of Mental Health and Neuro Sciences (2020, April). Mental Health in the times of COVID-19 Pandemic Guidance for General Medical and Specialised Mental Health Care Settings.

[13] Ornell, F., Schuch, J.B., Sordi, A.O., \& Kessler, F.H.P. (2020). Pandemic fear and COVID-19: mental health burden and strategies. Brazilian Journal of Psychiatry. 42(3). Retrieved from https://doi.org/10.1590/1516-44462020-0008.

[14] Panchal, N., Kamal, R., Orgera, K., Cox, C., Garfield, R., Hamel, L., Munana, C., Chidambaram, P. (2020, April 21). The Implications of COVID-19 for Mental Health and Substance Use. Kaiser Family Foundation. 